\title{
Large-Scale Urban Prototyping for Responsive Cities: A Conceptual Framework
}

\author{
Peter Buš* \\ Chair of Information Architecture, Department of Architecture, Institute of Technology in Architecture, Swiss Federal Institute \\ of Technology ETH, Zurich, Switzerland
}

Despite ubiquitous urbanization and worldwide standardization, there is a lack of better differentiation between cities toward more customized environments. Although current advancements in computational design and digital fabrication technologies have been successfully applied in various architectural scales, they have rarely, if ever, been implemented in a larger urban context that can lead to broader benefit and responses for citizens. This research aims to describe the potential of digital fabrication methods for large-scale urban applications that can subsequently lead to more diverse and unique urban environments. This paper summarizes state-of-the-art principles for large-scale building construction that have been implemented in the past, along with current research and practice, and outlines a conceptual framework for possible future directions for large quantities of automatic and bespoke construction deliveries for future customized urban scenarios. This article also outlines the effects of end-users' participation on urban developments using online users' interface to inform building processes. To address aspects of end-users' engagement in customization of cities, the article elaborates the question of responsiveness, where the citizen actively interacts with the environment and building technology and vice versa in order to customize the urban space. This is theoretically and conceptually explained and illustrated in a case study related to the formerly industrial harbor area of Tanjong Pagar in the city of Singapore, which is a test-bed for new urban developments on 325 ha of waterfront land in the downtown port area within the context of a tropical city.

Keywords: on-site participation, mass-customized cities, bespoke construction deliveries, large-scale urban prototyping, responsive cities

\section{INTRODUCTION AND PROBLEM STATEMENT}

Presently, many urban environments face problems with standardized production, repetition, and uniformity that lead to monotonous urban conditions with no unique qualities. Citizens, as primary end-users of urban environments have not been actively engaged in the planning or customization of cities, but this trend is slowly declining. The current research, design, and planning practices, apart from independent bottom-up urban activities, that have begun to consider and implement citizens' knowledge and information in order to customize permanent solutions, though they are no longer sufficient. Cities, as rapidly changing instances, and a change in social engagement and sharing of spaces, seek to adapt to the needs and desires of their citizens, defined in this article as end-users of customized urban spaces. 
Customization is defined as a process in which end-users are invited to physically modify, build, rebuild, configure, reconfigure, adapt, and spatially change their environment according to their demands, needs, or requirements. The article concentrates on the urban scale which is primarily understood as a portion of the city, a neighborhood within the city, an agglomeration of urban units (buildings and other elements) that form a coherent environment with unique qualitative properties.

The working hypothesis in this article is as follows: Scaling up fabrication technologies to an urban scale and active engaging of end-users in design and building processes will enable the construction of highly customized, diverse, distinctive, and livable urban environments that consider end-users' demands.

The link of digital fabrication technologies for prototyping large-scale urban interventions, the implementation of which may lead to unique and customized urban solutions, that Verebes describes as Distinctive Urbanism (Verebes, 2016) with users' engagement can be addressed in two ways:

- Through creating online user interfaces and collecting the information and environmental demands that will inform the digital building methods as a crowd-driven building strategy; and

- Through directly engaging end-users in building activities that utilize prefabricated and pre-cut elements to create on-demand customized urban scenarios, possibly through interactions with construction technologies.

\section{RESEARCH QUESTIONS}

However, research questions need to be addressed regarding the problem of prototyping and implementing mass-customized cities: How can citizens directly exert their desires and preferences on their environments to create better living conditions with the support of digital and fabrication technologies? Are the current digital manufacturing and fabrication technologies scalable for larger urban contexts (Verebes, 2015, p. 9-17)?

\section{RESEARCH AIMS}

Considering the above-mentioned research questions, this research mainly aims to

- Study, reveal, and examine the potential of digital fabrication techniques for large-scale application in urban construction;

- Outline their applicability in real-world conditions with respect to end-users' engagement considering current advancements in online digital interfaces for citizens and technological advancements in digital fabrication; and

- Discuss the potential of scaling-up of prototyping practices in urban contexts, and the role of citizens in on-site and off-site participation.

\section{METHODOLOGY}

The following methodologies have been proposed and applied in this study:
- Literature review, site visits, and visits to fabrication facilities;

- Qualitative research: conversations with design experts, selected academics, and design practitioners, and subsequent collection of data;

- Qualitative evaluation of the gathered data based on several criteria, such as practical applications, technological, and technical requirements, and limitations of the current technology; and

- A theoretical overview of possible directions for practical implementation of the conceptual framework for future largescale urban prototyping methods.

\section{PAST VISIONS AND PRESENT PRACTICES FOR CUSTOMIZED URBAN ENVIRONMENTS}

The following examples established the practice of structural modular assembly, employing predefined building blocks to create adaptive and flexible solutions based on customization of spaces.

\section{Early Ideas}

The concept of customization of urban spaces was envisioned by architects as far back as the late 1940s, e.g., Yona Friedman's La Ville Spatiale (Friedman et al., 2015), and even earlier concepts of pre-fabricated Fuller Houses, dated from 1920 to 1946. The principles of these projects were based on factory-engineered and assembled prefabricated components delivered to the site in large packages (Spyropoulos, 2013, p. 46-57).

Prefabricated modules and assemblies appear in many proposals today, such as in Richard Rogers' Aram Module or Zip House, following ideas of extensions, additions, mobility, and flexibility, previously employed by Cederic Price in his Fun Palace for the Joan Littlewood Project in London (1959-1961), which have been applied in the Center Georges Pompidou in Paris (Powell, 1994, p. 40-1; Rogers and Brown, 2017, p. 109-53).

Similarly, Rogers Stirk Harbor \& Partners' Leadenhall Building in London is a unique example of digital and automatic large-scale prototyping, consisting of prefabricated elements assembled on-site and based on multi-crowded design and planning intelligence (Krolikowski and Eley, 2014, p. 68-74; Rogers and Brown, 2017, p. 168-74).

\section{Utopias by Austrian Phenomenon, Metabolists, and Archigram}

The principle of large-scale supporting frameworks for megastructures with customized plugged-in volumes was applied and realized in Kurokawa's Plug-in Capsule House and in Kikutake's Expo Tower in 1970. The famous Plan for Tokyo was another reflection of a multi-layered interwoven infrastructural network, with embedded volumes within a predefined supporting grid proposed by Tange et al. (1960) in Spyropoulos (2013, p. 132-3). Kurokawa's Naganin Capsule Tower (1972) in Van Der Ley and Richter (2008, p. 23) further extrapolated the idea of prefabricated capsules assembled and placed, replaced, and modified as required. 
Eckhard Schulze-Fielitz, one of the main figures of the Austrian Phenomenon (Cook, 1970, p. 71), experimented with two and three-dimensional networks using prefabricated components, leading to non-repetitive sculptural architectures such as the Raumstadt project (1966). Another realization of modular units by Richard J. Dietrich created infinite possible configurations in the Metasdtadt-Bausystem in Munich (1970). Günter Domenig and Eilfried Huth developed a large-scale city megastructure based on mounted components in their Stadt Ragnitz project (1969) in Van Der Ley and Richter (2008, p. 176185), composed of a publicly funded supply grid with individually customized components inside.

Archigram's concepts elaborate these principles; the Plug-In City (1964) and the Computer City (1964) examined the plugin approach within the universal frame structure defined by the network and communication infrastructure. Moshe Safdie's Habitat (1967) in Montreal and Zvi Hecker's Ramot Housing in Jerusalem (1972-1985) are radical examples of prefabricated housing units assembled on-site and of the creation of unique urban configurations at a large scale (Spyropoulos, 2013, p. 65-87).

\section{PARTICIPATION AND DIGITAL FABRICATION METHODS}

To overcome insufficient information of local conditions (Keating et al., 2017), it is necessary to involve local end-users in the design and building processes, as observed in the past. Such an idea contradicts with large-scale and off-site manufacturing assembly lines that are implemented in the building industry as top-down automatic processes, e.g., the Design for Manufacture and Assembly method developed by Liang O'Rurke ${ }^{1}$ that aims to deliver 10,000 building units per year. This raises the question of the repetition and uniformity of units as fully equipped modules are either completely or nearly identical.

\section{Future Perspectives: Scalability of Digital Fabrication Methods Crowd-Driven Prefabricated Elements Toward Customized Urban Neighborhoods}

Building participation strategies and pre-fabricated small-scale elements for easy manipulation and delivery on-site would allow end-users to build their own customized scenarios following simple rules for assembly. Such a concept can be applied in informal settlements that leads to customized urban interventions. These designing and building strategies must utilize low-tech principles based on simplicity and participatory interventions understandable by non-experts. The capacity of such a system would allow users to improvise and, share their knowledge or skills and to activate local communities' liveliness leading to an improvement in local conditions using accessible resources in the environment.

As a consented outcome of such a crowd-driven design method needs to be defined, it would be necessary to integrate

${ }_{1}^{1}$ http://www.laingorourke.com/what-we-do/modular-manufacturing.aspx advanced evaluation data strategies to deliver the desired outcome amongst several co-participants. Customization does not necessarily imply a unique design outcome for an individual. Rather, it leaves open space for participation and provides a human touch, while considering human needs that change with time.

\section{Large-Scale Automatic Building Methods at an Urban Scale-Existing Technologies in Port Areas in Waterfront Cities With Crowd-Driven Building Strategies}

The existing large-scale shipping crane technologies in port areas in waterfront cities have the capacity to be adopted by the building industry as automatic construction systems for largescale urban interventions, for instance in city port areas being converted from industrial zones to new city centers. Crane automatic systems manipulating high payloads can be upgraded with additional multi-task or single-task robots and effectors to deliver a large quantity of bespoke built production driven by user interfaces. Users' engagement in such processes can be conducted via interface as an accessible, cloud-based on-line interactive digital environment, operable simultaneously from different locations by several users and stakeholders, used to deliver a consented scenario that is then sent to the construction system. The city building infrastructure reacts according to users' demands. This concept may be tested at scale in existing port areas. However, as it requires multidisciplinary cooperation, the challenge for the industry in such a scale-up will be to develop a collective multidisciplinary framework considering all technical aspects and logistics. This can be combined with additional building strategies and conventional building methods. Such a strategy is advantageous as existing systems are already placed on-site and there is no need to remove them from the ports.

Fabrication and construction systems that are interconnected via data clouds based on "multi-crowded intelligence" and control can be linked directly with end-users' applications to react appropriately to their requirements (Nolte and Witt, 2014, p. 829). This allows the technology to respond to citizens' demands and vice versa.

\section{Cable-Driven Systems Harnessed in a Robotic Network}

Another rapid large-scale prototyping method is based on cabledriven robotics such as RoboCrane, developed by the Robot Systems Division of the National Institute of Standards and Technology-(NIST) (Albus et al., 1992, p. 373-385). The system is available in several stages of modifications and scales and is mostly used in the shipping industry for maintenance or construction. A variation of the concept, the Flying Carpet, is capable of moving quickly and efficiently to cover a large vertical area of $24 \times 8 \mathrm{~m}^{2}$. Similar systems are being developed (LorenzoEiora et al., 2018² ; Crolla et al., 2018, p. 9-18; Sousa et al., 2016, p. 230-9) for printing, laser cutting or assembling cable-driven systems. In principle, cable-driven kinetic robotic systems may be harnessed in a multiple-system network consisting of a series of

${ }^{2}$ http://www.e-architects.net/SiteSpecific3dPrinter-e-ChaiseLongue.htm 
interconnected robots will be capable to deliver large-scale urban scenarios. Each robot can operate as a single or multiple-task system. The challenge for the industry lies in the development of interactive and cooperative logistics between particular effectors to work on specific building or assembling tasks.

Cable driven robots are effective in the sense that they can cover larger areas. Their ability to be attached to an existing construction system and the fact that they do not need specific foundation, makes them very flexible, efficient, and transportable. The capacity of cable-driven systems interconnected in the network has the potential to be applied in large scale urban areas, such as informal settlements or in post-disaster scenarios where the need to rapidly build shelters is urgent.

\section{ABCS and RCACS-Based Sky Factories}

Systems such as the Automatic Building Construction System (ABCS) can harness twenty robots to work simultaneously in order to produce three-dimensional units in an assembly line, based on the advanced plug-and-play approach (Bock, 2016, p. 116-122). Robotic and Crane Based Automated Construction Systems (RCACS) (Ikeda and Harada, 2006, p. 722-727; Kang et al., 2015, p. 670-671) apply factory automation, along with robotics and computer technology to construction processes. These on-site factories are capable of delivering large quantities of building production by combining robotics and conventional construction methods. However, as Gambao et al. (1999) states in (Sousa et al., 2016, p. 233), "these big and heavy robots are difficult to transport [...], and require a very high investment." In highdensity urban areas where the population is growing, it would be able to react to local necessities and decisions at a large-scale, such as operating on various buildings at the same time in the context of high-rise buildings and without any disturbance of existing city activities. Sky factories will allow the creation of more flexible and diverse environmental and architectural conditions.

\section{Robotic Swarms}

The system known as Aerial Additive Building Manufacturing (Dams et al., 2017) consisting of small-scale construction robots in the form of flying swarms will deliver constructions for a variety of situations, e.g., in post-disaster scenarios ${ }^{3}$. Such a strategy requires advanced sensing and direct cooperation between swarm units, e.g., drones, that are capable to cooperatively behave on-site. The potential will allow the employment of a large number of cooperating swarm robots (either flying or operating on the ground) to deliver large-scale scenarios using a variety of technologies, such as 3D printing or assembling the components (Andréen et al., 2016, p. 54-61; Pantazis and Gerber, 2017, p. 75-84). The self-assembling and self-organizing robots themselves as building blocks with the capacity to change the morphology of the architectural or urban scenario according to the demands of the users as programable building agents are currently being developed and tested in several academic institutions. They explore forms of customized urban interventions based on assembled discrete elements, ondemand co-living housing blocks, citizens' participation, and

${ }^{3} \mathrm{http}: / /$ www.aerial-abm.com/ engagement of different models of ownership, construction, and inhabitation (Köhler, 2017, p. 523-532; Claypool and Ameijde, 2018; Vanucci and Muzychak, 2018). This led to new building strategies, changing the character of permanent built scenarios to highly flexible and customizable environments according to change of building programs and spatial demands.

\section{Vision for Tanjong Pagar Singapore, 2080+}

The idea of large-scale prototyping incorporating contributions from citizens' designs or decisions (Mueller et al., 2018) were conceptually and computationally tested by the research team of the Chair of Information Architecture ETH in a case study that investigated the Singapore's Tanjong Pagar waterfront area. The area is being converted from an industrial harbor into a new technological, cultural, commercial, and residential hub (Figure 1).

\section{Computational Model}

The aim of the study was to test the potential of computational user's interface to deliver large number of urban scenarios based on bottom-up design strategy (Supplementary Video 1). Our inhouse developed users' interface integrates a library of spatial components that are operable by the end-users in order to provide demanded spatial aggregations. The scenario adapts constantly according to the bottom-up requirements. As such, it brings the potential of responsive urban neighborhood to be explored and discussed among the authorities.

As it is observable from the visual results, the environments can be built from prefabricated components assembled on-site or by means of pre-defined proto-assemblies. The end-user is allowed to customize a spatial scenario and submit it via an online interface to inform other citizens, experts, and authorities.

In addition, the proposal addresses the utilization of existing shipping crane systems as a potential framework for the installation of on-site digital fabrication systems being integrated as a part of the city infrastructure (Figure 2). By combining this with participatory design activities via user' interfaces (Buš et al., 2018, p. 153-8), a variety of open-ended forms of urban and architectural interventions can be designed (Supplementary Figures 1-7). In this concept, the shipping cranes are adopted for use in construction and are connected to the Internet of Things as automatic programmable building technology responding to users' needs or program changes.

\section{Tanjong Pagar Scenario: Challenges for Future Development}

However, although the crowd-driven user interface delivers a variety of spatial outcomes in a digital model, there are challenges present in large-scale prototyping which needs to be examined in future research:

- Localization of the building system at the construction site will be achievable by incorporating and deployment of sensors, moving or static to inform the current status of the scenario. Data collected will be stored and evaluated on cloud to inform the construction systems;

- Contextual awareness of other components at the construction site as well as adjacent components artificially controlled and 


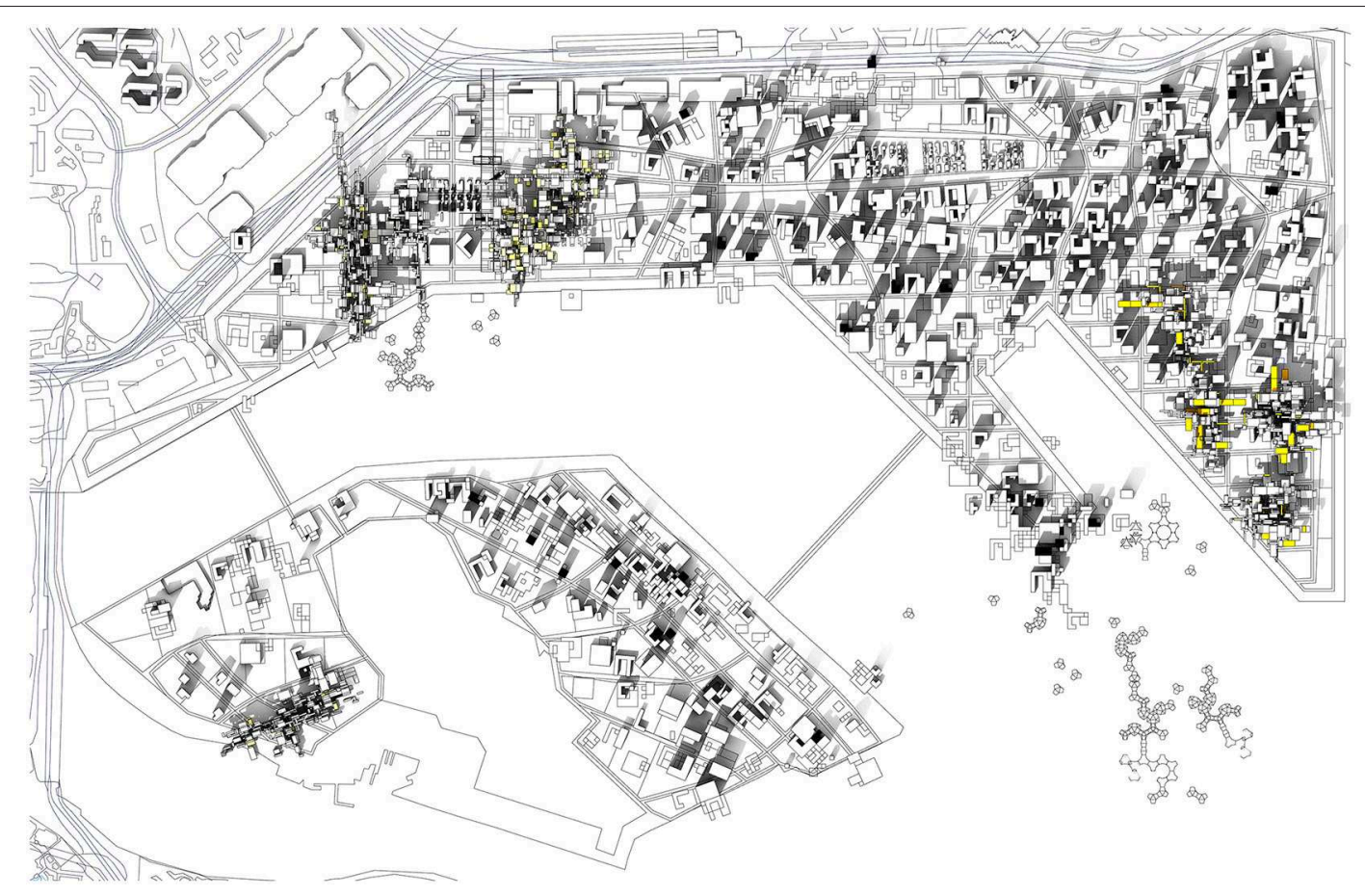

FIGURE 1 | An initial proto-masterplan for the adaptive city of Tanjong Pagar waterfront area in Singapore with customized responsive neighborhoods.

aware of other components within the cluster (Loveridge and Coray, 2017);

- Work precision (while taking a high technology approach), though not necessary at all times and in all cases;

- Human-machine interfaces and interactions;

- Information exchange between platforms, designers, experts, workers in design and building processes, and end-users through the Internet of Things;

- Prototyping of urban logistics with citizen-driven foresight and planning, which requires the engagement of multidisciplinary experts (Graham et al., 2015, p. 341-52).

\section{CONCLUSION}

This article outlines concepts of technological democratization in building processes for future urban environments by linking building and fabrication technologies with human needs, factors, and conditions using the interactive urban model interface, operating with a variety of possible scenarios. Although this concept of crowd-driven design and construction to customize urban spaces outlines a positive scenario for cities in the near and distant future, it must be critically reevaluated and revised from different perspectives, especially from the technical and logistics requirements. Although the article does not provide comprehensive evidence for the applicability of such strategies in full-scale urban conditions, the hypothesis cannot be confirmed at this stage of the research, and it is clearly observable from the existing state-of-theart fabrication methods, currently accessible technologies, and literature review, that such a strategy is feasible. However, deeper technological research is necessary for the realization of such strategies.

The article summarizes the following building approaches for large-scale construction (Supplementary Table 1):

- Applications of existing digital fabrication technologies in current large-scale industrial environments such as harbor areas at city ports in waterfront cities using the current harbor crane systems for shipping deliveries was outlined. These can be modified and adopted for building constructions, with the attachment of specific multi-tasks or single-tasks robots. However, the flexibility of such systems is constrained to precision and advanced urban logistics;

- Cable-driven kinetic systems deployed on large-scale urban sites was introduced as construction delivery method for multi-task purposes. The system can be attached to existing constructions or operate within predefined frameworks and can even create a network of large quantities of working effectors delivering multiple customized constructions in different levels of detail;

- Pre-cut elements, digitally prefabricated off-site and delivered on-site for crowd-driven building methods. The crowd can create multiple options for an assembly in larger customized urban scenarios following the rules of assembly;

- Implementation of interconnected sky factories for highrise buildings as interactive building construction methods addressing social and environmental shifts and demands in 


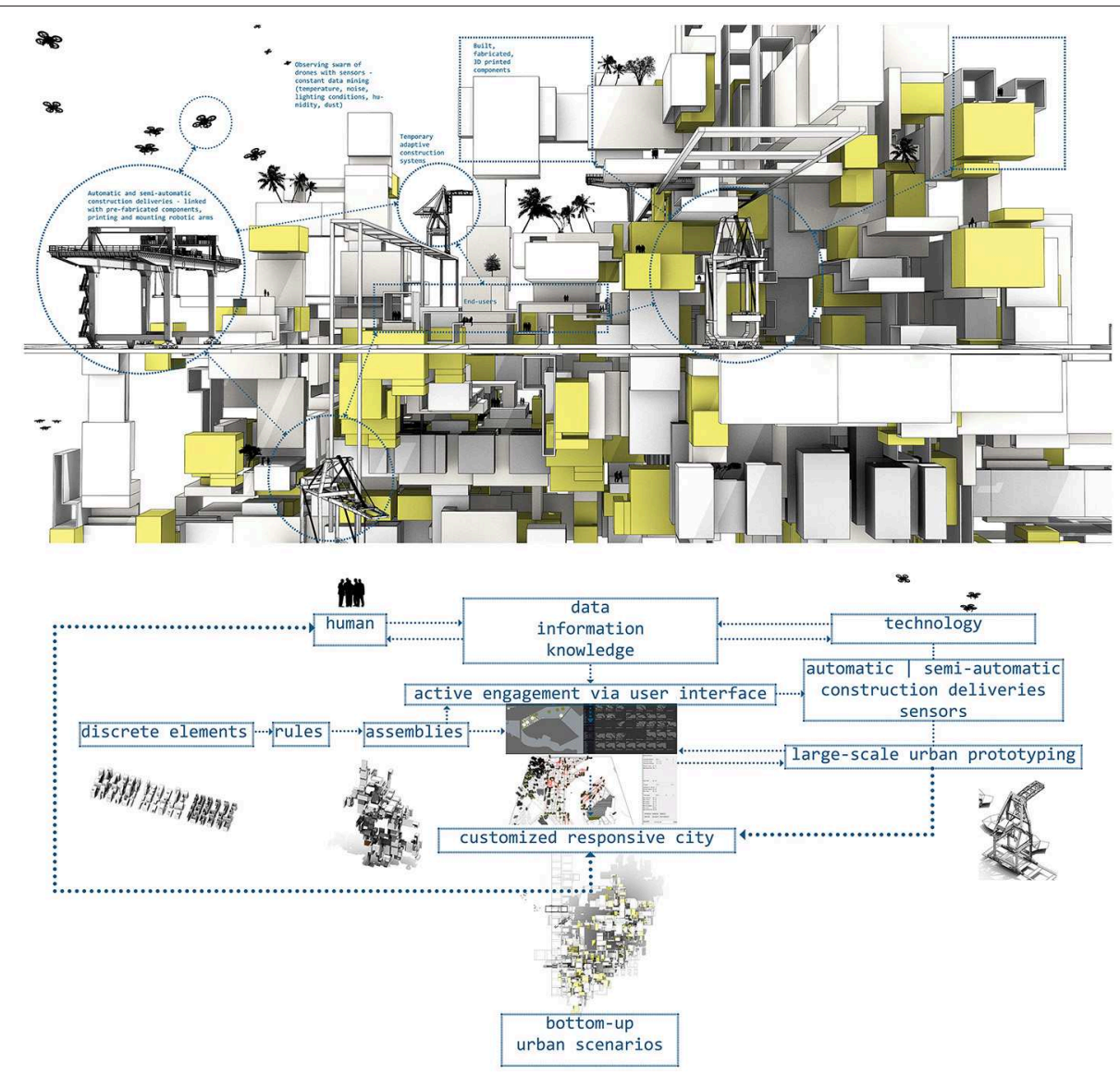

FIGURE 2 | Scaffolding and supporting systems as an integrated part of the city infrastructure. Perspective view of the adaptive neighborhood with the process illustrating the relations between particular components in the responsive city.

high-density cities were described. Such systems can vary in size, application, form, and function. They require high investment; and

- Robotic swarms flying or operating on the ground that are capable to construct, print or assemble themselves as independent building agents. However, the system requires advanced technological development, which is far from the aspects of simplicity or low-tech principles comprehended by non-expert users.

Furthermore, it is necessary to point several remarks related to large-scale prototyping methods:

- Design for the manufacture and assembly method must integrate customization in order to avoid repetition of components and allow for a wider variety of outcomes.

- "Technology does not solve all problems in urban environments." The participatory engagement of citizens in building processes addresses the needs of citizens as users, but it also prompts questions regarding "design control" and the role of a designer as an expert vs. the role of a non-expert as a designer, as stated by Prof Verebes during a conversation with the author on March 27, 2018;
- The notion of adaptability of a customized urban space according to end-users' needs raises questions concerning the role of technology employed in the processes, specifically low-tech vs. high-tech approach. There is immense scope for improvisation, sharing, collaboration and interaction between humans and machines. Combining low-tech and high-tech principles may lead to broader and more distinctive urban order and an amplification of specific local urban identities;

- "Scaffoldings and movable supportive constructions can serve as a permanent, integrated part of a city's infrastructure" that will always be ready to function in building processes or behave as inhabitable instances, as highlighted by Köhler in personal communication with the author on April 13, 2018; and

- Conceptually, a building's technology can respond to end user's needs once linked with their digital online interfaces for customization as a part of the Internet of Things.

\section{CREDITS FOR THE VISION FOR TANJONG PAGAR 2080+ PROJECT}

Proto-masterplan for Tanjong Pagar 2080+, 325 ha site, South waterfront in Singapore was a competition entry submitted for 
the 7th Architecture Contest Responsive City in January 2018, organized by the IAAC-Institute for Advanced Architecture of Catalonia, Barcelona, Spain.

Research and Design Team: Chair of Information Architecture, Department of Architecture, ETH Zürich, Peter Buš (design director, scripting, post-production, research), Lukas Treyer (programming), Chang Mei-Chih (design, scripting), Ayça Tartar (research), Jin Li (postproduction).

\section{AUTHOR CONTRIBUTIONS}

The research has been conducted by PB himself, as an independent Richard Rogers Fellowship fellow during his residency in London, spring 2018. All other sub-contributors related to the illustrated case study are mentioned in the Credits section in the main text.

\section{FUNDING}

This research has been conducted during the author's Richard Rogers Fellowship residency in Spring 2018 in London, awarded and supported by the Harvard University Graduate School of Design. The competition entry Proto-masterplan for Tanjong

\section{REFERENCES}

Albus, J., Bostelman, R., and Dagalakis, N. (1992). The NIST spider, a robot crane. J. Res. Natl. Inst. Stand. Technol. 97, 373-385. doi: 10.6028/jres.097.016

Andréen, D., Jenning, P., Napp, N., and Petersen, K. (2016). "Emergent structures assembled by large swarms of simple robots," in Acadia 2016 Posthuman frontiers: Data, Designers, and Cognitive Machines, eds K. Velikov, S. Manninger, M. del Campo, S. Ahlquist, and G. Thün. (Ann Arbor, MI: Association for Computer Aided Design in Architecture ACADIA), 54-61.

Bock, T. (2016). Construction robotics. J. Robot. Mechatron. 28, 116-122. doi: 10.20965/jrm.2016.p0116

Buš, P., Treyer, L., and Tartar, A. (2018). "Customised floating neighbourhoods: design interfaces for non-experts and designers to explore emergent floating formations," in CAADRIA 2018 Learning, Prototyping and Adapting, Proceedings of the Short Papers of the 23rd International Conference on Computer-Aided Architectural Design Research in Asia, eds W. Huang, M. Williams, D. Luo, Y. Wu, and Y. Lin. (Hong Kong: The Association for Computer-Aided Architectural Design Research in Asia CAADRIA), 153-158.

Claypool, M., and Ameijde, J. (2018). Wall text, Disruptive Architectures. UCL Bartlett School of Architecture Summer Show London.

Cook, P. (1970). Experimental Architecture. New York, NY; London: Universe books.

Crolla, K., Cheng, P. H. H., Chan, D. Y. S., Chan, A. N. F., and Lau, D. (2018). "Inflatable architecture production with cable-driven robots," in Learning, Adapting and Prototyping-Proceedings of the 23rd CAADRIA ConferenceVolume 1, eds T. Fukuda, W. Huang, P. Janssen, K. Crolla, and S. Alhadidi. (Hong Kong: The Association for Computer -Aided Architectural Design Research in Asia CAADRIA), 9-18.

Dams, B., Sareh, S., Zhang, K., Shepherd, P., Kovac, M., and Ball, R. J. (2017). "Aerial additive building manufacturing: three-dimensional printing of polymer structures using drones," in Proceedings of the Institution of Civil Engineers - Construction Materials (ICE). doi: 10.1680/jcoma.17. 00013

Friedman, Y., Orazi, M., Seraj, N., and Veillon, C. (eds.). (2015). Yona Friedman. The Dilution of Architecture. Zürich: Park Books.
Pagar 2080+ was supported by the Chair of Information Architecture ETH Zurich.

\section{ACKNOWLEDGMENTS}

The author would like to extend his gratitude toward Prof. Mohsen Mostafavi, Harvard University Graduate School of Design team and Prof. Dr. Gerhard Schmitt (Singapore ETH Centre, Chair of Information Architecture ETH Zürich) for their support, along with all partners in conversations and presentations, namely Prof. Dr. Tom Verebes (OCEAN CN), Prof. Dr. Michael Weinstock (EmTech AA) and his research team, Sir Richard Rogers, Mr. Simon Smithson and the team at Rogers Stirk Harbor and Partners, Mr. Gavin Thomson and Mr. Robert Moyser (BuroHappold Engineering), Mr. Josef Musil and Mr. Simon Hicks and the team of Specialist Modeling Group at Foster and Partners, Dr. Irina Davidovici (ETH Zürich), Dr. Daniel Köhler (UCL Bartlett), and Mr. Martin Gsandtner (Zaha Hadid Architects).

\section{SUPPLEMENTARY MATERIAL}

The Supplementary Material for this article can be found online at: https://www.frontiersin.org/articles/10.3389/fdigh. 2019.00001/full\#supplementary-material

Gambao, E., Balaguer, C., and Gebhart, F. (1999). "A robotic system for automated masonry," in Automation and Robotics in Proceedings of the 16th IAARC 1999, 599-602. doi: 10.22260/ISARC1999/0093

Graham, G., Mehmood, R., and Coles, E. (2015). Exploring future cityscapes through urban logistics prototyping: a technical viewpoint. Supply Chain Manage. 20, 341-352. doi: 10.1108/SCM-05-2014-0169

Ikeda, Y., and Harada, T. (2006). "Application of the automated building construction system using the conventional construction method together," in Proceedings of the 23th International Symposium on Automation and Robotics in Construction, ISARC 2006, ed D. Gakkai (Tokyo: Waseda University), 722-727. doi: 10.22260/ISARC2006/ 0134

Kang, T. K., Nam, C., Lee, U. K., Doh, N. L., and Park, G. T. (2015). “Development of robotic-crane based automatic construction system for steel structures of high-rise buildings," in Proceedings of the 28th International Symposium on Automation and Robotics in Construction, ISARC 2011 (New York, NY: Curran), 670-671. doi: 10.22260/ISARC2011/0125

Keating, J. S., Leland, C. J., Cai, L., and Oxman, N. (2017). Toward site-specific and self-sufficient robotic fabrication on architectural scales. Sci. Robot. 2:5. doi: $10.1126 /$ scirobotics.aam8986

Köhler, D. (2017). "The city as an element of architecture - Discrete automata as an outlook beyond bureaucratic means," in 35th eCAADe Conference ShoCK! - Sharing Computational Knowledge!, eds. A. Fioravanti, S. Cursi, S. Elahmar, S. Gargaro,G. Loffreda, G. Novembri, and A. Trento (Rome: eCAADe and Sapienza University of Rome), 523-532.

Krolikowski, D., and Eley, D. (2014). "The leadenhall building: design for fabrication-digital workflow and downstream fabrication system," in Fabricate: Negotiating Design \& Making 2014, eds. F. Gramazio, M. Kohler, and S. Langenberg (London: UCL Press), 68-74.

Loveridge, R., and Coray, T. (2017). Robots on construction sites: the potential and challenges of on-site digital fabrication. Sci. Robot. 2:5. doi: 10.1126/scirobotics.aan3674

Mueller, J., Lu, H., Chirkin, A., Klein, B., and Schmitt, G. (2018). Citizen design science: a strategy for crowd-creative urban design. Cities 72, 181-188. doi: 10.1016/j.cities.2017.08.018 
Nolte, T., and Witt, A. (2014). Gehry Partners' Fondation Louis Vuitton: Crowdsourcing Embedded Intelligence. Arch. Des. 1, 82-89. doi: 10.1002/ad.1705

Pantazis, E., and Gerber, D. (2017). "Emergent order through swarm fluctuations - A framework for exploring self-organizing structures using swarm robotics: emergent structures assembled by large swarms of simple robots," in 35th eCAADe Conference ShoCK!-Sharing Computational Knowledge!, eds A. Fioravanti, S. Cursi, S. Elahmar, S. Gargaro,G. Loffreda, G. Novembri, and A. Trento. (Rome: eCAADe and Sapienza University of Rome), 75-84.

Powell, K. (1994). Richard Rogers. London: Ellipsis London Pr Ltd.

Rogers, R., and Brown, R. (2017). A Place for all People: Life, Architecture, and Fair Society. Edinburgh; London: Canongate Books.

Sousa, J. P., Palop, C. G., Moreira, E., Pinto, A. M., Lima, J., Costa, P., et al. (2016). "The SPIDERobot: a cable-robot system for on-site construction in architecture," in Robotic Fabrication in Architecture, Art and Design 2016, eds D. Reinhardt, R. Saunders, and J. Burry. (Cham; Heidelberg; New York, NY; Dordrecht; London: Springer International Publishing Switzerland), 230-239. doi: 10.1007/978-3-319-26378-6_17

Spyropoulos, T. (ed.). (2013). Adaptive Ecologies: Correlated Systems of Living. London: Architectural Association and the Authors.
Van Der Ley, S., and Richter, M. (eds.). (2008). Megastructures Reloaded: Visionary Architecture and Urban Design of the Sixties Reflected by Contemporary Artists. Ostfildern: Hatje Cantz Verlag.

Vanucci, M., and Muzychak, A. (2018). Wall Text, Tabula Automata Material Life III, Architectural Association Project Review Exhibition. London.

Verebes, T. (2015). Cities and their specificities: standards, customs and the making of 21 st -century urbanity. Arch. Des. 6, 9-17. doi: 10.1002/ad.1971

Verebes, T. (2016). The interactive urban model: histories and legacies related to prototyping the twenty-first century city. Front. Digit. Humanit. 3:1. doi: 10.3389/fdigh.2016.00001

Conflict of Interest Statement: The author declares that the research was conducted in the absence of any commercial or financial relationships that could be construed as a potential conflict of interest.

Copyright (c) 2019 Buš. This is an open-access article distributed under the terms of the Creative Commons Attribution License (CC BY). The use, distribution or reproduction in other forums is permitted, provided the original author(s) and the copyright owner(s) are credited and that the original publication in this journal is cited, in accordance with accepted academic practice. No use, distribution or reproduction is permitted which does not comply with these terms. 